\title{
Antecedents and consequences of uncertainties perceived by finance professionals
}

\section{Vasudha Chaudhari, Allison Littlejohn and Simon Cross}

\section{I7.I Introduction}

Uncertainty is an inherent component of the modern-day workplace (Brown et al., 2011). It is a major area of interest within the field of management, change management, and organisational learning (Bohlinger et al., 2015a; Downey \& Slocum, 1975; Markowska \& Wiklund, 2020). During ambiguous times, professionals need to learn to navigate their work lives through various uncertainties, as, for example, also illustrated in Chapter 18 (Iwaniec-Thompson, 2022). The ability to learn in uncertainty can be considered from two perspectives - individual learning that shapes the individual performance (micro perspective) and organisational learning that defines organisational success (macro perspective). However, much of the existing literature tends to focus on the macro perspective of the organisations (see, e.g., Michel \& Wortham, 2009; Zhao \& Wang, 2020). There are a few examples that combine the micro and macro perspective. For example, Wang et al. (2019) found that individual unlearning mediated by organisational unlearning (i.e., discard work practices that are no longer relevant or serve their purpose) and relearning (i.e., ability to forget practices gained from old knowledge and relearn new practices) has a positive effect on strategic flexibility. This means that strategic flexibility, which is an indicator of an organisation's ability to succeed in an uncertain environment (Bock et al., 2012), depends on the professionals' ability to learn, unlearn, and relearn. Hence, there is a need to focus on unpacking the individual learning processes in uncertainty.

The uncertain nature of workplaces warrants that professionals take charge of their workplace learning activities (Billet, 2011; Fenwick, 2001) and self-regulate their learning (Fontana et al., 2015; Margaryan et al., 2009). There is a growing body of research exploring the intersection between working, learning, and uncertainty (Bohlinger et al., 2015b; Markowska \& Wiklund, 2020). However, there is limited focus on the professionals' perception of uncertainty. In particular, it is unclear how professionals conceptualise uncertainty in their workplace, the antecedents and consequences of the uncertainties they perceive, how they manage to learn during uncertainty, and the challenges they face in doing so. Examining these aspects are essential, as understanding how professionals perceive and learn in 
uncertainty have implications for their job satisfaction and personal well-being (Fløvik et al., 2019).

Most existing research on uncertainty in organisational contexts has concentrated on the impact of environmental uncertainty on organisational factors such as strategic foresight (Vecchiato \& Roveda, 2011), entrepreneurial decision-making (McKelvie et al., 2011), or innovation (Freel, 2005). In their seminal work on organisational theory and organisational learning, March and Olsen (1975) highlighted the importance of studying learning processes from an individual perspective. However, there have been surprisingly few studies that were conducted in the field of learning in uncertainty, especially from an individual perspective.

A problem that exists in fully understanding the concept of learning in uncertainty is the complexity associated with defining the objective and perceptual parameters of the environmental uncertainty. Weiss and Wittmann (2018) assert that in order to gain a holistic understanding of environmental uncertainty and the associated cognitive processes, it is essential first to establish the objective/tacit factors that define the nature of uncertainties within the research context and then to examine the perceptual factors. However, the tacit factors are context-dependent and subject to change with time (Hertati, 2015; Vanevenhoven, 2012). The analysis presented in Chapter 17 is part of a larger research study that sought to examine the relationship between self-regulated learning (SRL) and perceived environmental uncertainty (PEU) of finance professionals (Chaudhari, 2020). The research findings in Chapter 17 constitute the preliminary study undertaken to explore the nature of uncertainties within the finance sector and how the finance professionals perceived the antecedents and consequences associated with that uncertainty.

\section{I.I Uncertainty in the finance sector}

The distinction between risk and uncertainty in finance is rarely made (Gigerenzer, 2018). Traditional finance literature encompasses the objective nature of uncertainty by focusing on the quantitative measures of risk (e.g., probability models, stochastic programming), with a fundamental assumption of a linear relationship between risk and return (Jo \& Sekkel, 2019). However, there is an emerging body of literature in behavioural finance that examines the subjective aspect of uncertainty in which decision maker's perception of uncertainty is a substantial aspect of defining and understanding the processes of decisionmaking, innovation, and learning in uncertainty (Dow, 2010; Muradoglu \& Harvey, 2012). In this study, uncertainty is conceptualised as per Milliken's (1987) framework of PEU. Ashill and Jobber (2010) identified three variants within the two categories of objective and perceptual measures of environmental factors in Milliken's (1987) framework - (1) measurement of individual environmental characteristics; (2) measuring the perceptions about the uncertainty; and (3) a composite measure. In their review of literature, they noted varied sources of objective environmental uncertainties. Perception of uncertainty is related to the objective environmental uncertainty (Weiss \& Wittmann, 2018), which is subject to change with time and context (Hertati, 2015). 
Before examining the learning processes in uncertainty, it was essential to establish the antecedents and consequences of uncertainties within the research context and how professionals perceived them. The present study addresses that gap by examining how the finance professionals perceive the environmental uncertainties in terms of their antecedents and consequences. In doing so, Chapter 17 answers the following research question: What are the antecedents and consequences of workplace environmental uncertainty perceived by finance professionals?

\section{7.2 Methods}

\subsection{Settings and participants}

The "Finance sector" is a broad term encompassing varying domains. Typically, very few organisations operate in all these domains, and ones that do are globally distributed. With a view of interviewing participants from different domains of the finance sector, the Chartered Institute of Securities and Investments (CISI) - an independent body that is responsible for professional training and development of finance professionals was selected as the research site for conducting this study. It provided access to individuals who experienced a broad range of uncertainties in the finance sector.

Selection of participants ensured an equal balance of practitioners and experts within the various sub-domains, to incorporate multiple perspectives from practice and academia. The distinction between "practitioners" and "experts" is based on industry terminology rather than academic classification. As per CISI's definition, practitioners were professionals who are currently active in the finance industry. In contrast, experts were either academics who conducted research in the finance sector or organisational heads who possessed in-depth insights into the uncertainties in the global financial sector. This distinction certainly does not imply that experts lacked practical experience or that practitioners did not have domain expertise, yet there is value in making the explicit distinction between experts and practitioners. In mapping the professional learning journey from novice to expert, Boshuizen et al. (2006) assert that, "experts do not just know more than novices, they also have a different way of structuring their domainspecific knowledge", and that experts can provide a "certain (very successful) perspective on a particular domain" (p. 6). Hence the intention of the sampling strategy was to ensure as diverse perspectives as possible through maximum variation sampling (Suri, 2011).

Based on the criteria outlined above, nine professionals were identified, two of them were female, and seven were male. As finance is a typically male-dominated industry, this sample was representative of CISI membership. Interview participants were categorised based on their expertise, knowledge of the specific domain, and their practical knowledge of the sector. The average work experience of the experts was 33 years, while the practitioners was 15 years. 


\subsubsection{Semi-structured interviews}

Qualitative interviews allowed for capturing in-depth insights into professionals' experiences and perceptions of uncertainty. They also provided flexibility in terms of time and methods of participation - face to face or online interviews thus making them the appropriate choice for answering the research question. All the interviews were recorded on a voice recorder and transcribed, coded and analysed by the researchers using NVivo 12 software (Woolf \& Silver, 2017). A combination of thematic analysis (Braun \& Clarke, 2019) and qualitative content analysis (Mayring, 2014) was employed to analyse the interview data.

\subsection{Results}

\subsection{Common themes between experts and practitioners}

\subsection{I.I Antecedents to uncertainty}

As indicated in Table 17.1, the most commonly prevalent perception was that the lack of knowledge was the main precursor to uncertainty. This is expected given the definition of uncertainty itself is the state of not knowing. For example, when talking about the MiFID II (Markets in Financial Instruments Directive) regulations, Participant E4 said that:

Table I7.I Summary of findings

\begin{tabular}{|c|c|c|}
\hline \multicolumn{3}{|c|}{ Common themes between experts and practitioners } \\
\hline $\begin{array}{l}\text { Consequences of } \\
\text { uncertainty }\end{array}$ & \multirow{2}{*}{\multicolumn{2}{|c|}{$\begin{array}{l}\text { Lack of knowledge } \\
\text { Fluctuations in the market } \\
\text { Role of technology } \\
\text { Lack of communication } \\
\text { Market Crash } \\
\text { Regulatory Changes } \\
\text { Reassessment of risk models } \\
\text { Financial opportunity } \\
\text { Learning opportunity }\end{array}$}} \\
\hline Perception of uncertainty & & \\
\hline \multicolumn{3}{|c|}{ Differences in perception of experts and practitioners } \\
\hline & Experts & Practitioners \\
\hline Antecedents of uncertainty & $\begin{array}{l}\text { Lack of trust } \\
\text { Disconnect with } \\
\text { academic world }\end{array}$ & \\
\hline $\begin{array}{l}\text { Consequences of } \\
\text { uncertainty }\end{array}$ & & $\begin{array}{l}\text { Lack of trust } \\
\text { Changes in training } \\
\text { requirement }\end{array}$ \\
\hline Perception of uncertainty & & $\begin{array}{l}\text { Uncertainty as something } \\
\text { to be avoided (negative } \\
\text { perception) }\end{array}$ \\
\hline
\end{tabular}


...with all regulation there is a certain amount of interpretation that a firm has to make. So, it is quite challenging for a firm. I think that is where the uncertainty comes in is in not knowing how to interpret that guidance.

(Participant E4)

Another theme that was persistently present in all the interviews was the uncertainty caused due to fluctuations in the market. Given that finance professionals have to deal with the highly volatile and ambiguous nature of the economic markets, it was not surprising that market uncertainty was perceived as one of the common antecedents to uncertainty in the workplace.

Additionally, the role of technology was also mentioned by all the participants as being responsible for introducing uncertainty in their workplace. From blockchain based services to robo-advisory platforms, professionals cited technology as a dominant antecedent to uncertainty in various contexts. For instance, Participant E2 cited wealth management advice-giving robots as bringing uncertainty for practitioners. There were also examples of algorithms driving financial decisions that cause uncertainty for professionals, as evidenced in the quote below:

Ya, I mean the other interesting dimension is that it is increasingly becoming a less human problem. So, you know all about the amount of activities being allocated to algorithms. So, people don't adapt perfectly to market conditions, we know that from experience. But what we don't know yet, is particularly how will the algorithms that are taking note of this activity, how they respond to significant event, and how they interact with each other.

(Participant P1)

Similarly, eight out of the nine participants reported lack of communication to be an important factor in increasing the perception of uncertainty amongst professionals. The scale of this lack of communication varied widely from a communication gap between two nations to two or more individuals who were decision-makers. For example, the issue of people working in silos and therefore not always alert to issues external to their work environment was mentioned by one respondent (Participant E2). Likewise, Participant P3 shared a key issue highlighted in the Northern Rock crisis report was the lack of communication between the supervisors and management.

\subsection{I.2 Consequences of uncertainty}

Similar to antecedents, there were some common prevalent themes reported by experts and practitioners. For example, all the professionals gave an example of a market crash following a period of economic or political uncertainty. The most commonly cited among those were the UK Sterling International Monetary Fund crisis. Similarly, regulatory changes as a consequence of a period of uncertainty were cited as one of the common consequences of uncertainty by all the professionals. In explaining how Basel I, II, and III regulations came about, Participant E2 
mentioned that "every piece of uncertainty resulted in unexpected volatility and downside returns, resulted in more and more regulations". The experts' view on consequences of uncertainty was mirrored by the practitioners with additional details about how the regulations imposed as a result of uncertainty had a trickledown impact on the marketplace, as evidenced by the quote below:

... [a period of uncertainty] subsequently led to a period of key regulation in financial market. And that key regulation resulted in the separation between alpha and beta and the leverage of both of those.

(Participant P3)

Almost all the professionals (eight out of nine) reported reassessment of risk models as a consequence of market uncertainty. This shows that uncertainty was perceived as a learning opportunity, where the lessons learnt from uncertain times were incorporated into the economic models, thus converting future uncertainties into risk. Since the definition of risk is to be able to assign probabilities to events, learning from uncertainty events and feeding that information into the economic models provided data for the future, thus converting the future uncertainties into risk. In relating his experiences of the 1987 market crash, Participant E5 elaborated on the process of how the uncertainty caused by the crash lead to reassessment of risk models and the impact it had on the market:

...lead people to reassess not only their risk models, but their interpretation of probabilistic estimates and returns and indeed what to do next in terms of asset allocation and so forth and whether any of the previous models worked.

(Participant E5)

\section{7.3.I.3 Perception of uncertainty}

All the professionals perceived uncertainty as a financial opportunity. However, closer investigations of these examples that were cited as uncertainty being a financial opportunity related to the professionals' predisposition to think of uncertainty in terms of risk. For example, Participant E4 rationalised his viewpoint that uncertainty is a financial opportunity with the following argument:

Traditionally uncertainty represents risk and risk has a trade-off through returns. But people are not focusing on returns at the moment, they are only fixing on the risks. So that certainly is new - this relationship between risk and return is manifesting itself in the way that it should. I mean, we got free money basically from Central Banks.

(Participant E4)

All the professionals also reported examples of uncertainty where they perceived it as a learning opportunity. These were mostly examples when the organisations/ individuals were unsuccessful in managing the uncertainty. This means that when 
they failed to manage uncertainty, they viewed it as a learning opportunity. The following quote demonstrates an example given by a regulator when they were handling a 'full-blown financial crisis spilling over to the whole economy'.

... These are not really Basel compliant, but this is something we felt that our market needed at that time, because of the specific risk that we faced. And as I said, it was too little too late - we were blamed when the whole thing started to fall apart. But we subsequently learned from this incident.

(Participant P3)

Although the experts and practitioners shared some common perceptions about antecedents, consequences, and ways in which they perceived uncertainty, they also had some differences which will be discussed in the following section.

\subsubsection{Differences in perception of experts and practitioners}

\subsubsection{Antecedents to uncertainty}

A crucial difference between the experts and practitioners was that experts believed that lack of trust was an important antecedent to uncertainty, while practitioners believed that it was a consequence of uncertainty. Of the 35 items coded to this theme, 26 were from experts and only nine were from practitioners. Participant E5, who was a senior adviser, recounted how a period of uncertainty brought about the breakdown of trust between buyers of the firm and the employees:

Trust was key and that created a big problem.... So, trust broke down and some bad things happened. I mean people did quite really naughty things about 20-30 years ago which created real uncertainty.

(Participant E5)

Similarly, a disconnect to the academic world was reported as a precursor to uncertainty 15 times out of 21 by experts.

...I blame it (lack of information) on our lack of contact with academic world. However, exactly because the academic world knows more about the history and what is happening around the world, and how Lehman used to overcome things. They could have probably suggested earlier that they see bad trends, that in other countries they dealt with in a certain way. So probably we should have had more contact with the academic research centres.

(Participant E4)

\section{7.3.2.2 Consequences of uncertainty}

A key difference in the way experts and practitioners perceived antecedents and consequences to uncertainty was that practitioners were more likely to emphasise the consequences of uncertainty, whereas experts dwelled on the causes and lessons 
learnt. Of the 28 instances of statements coded to the theme of changes in training requirements preceding a period of uncertainty, 22 were made by the practitioners, whereas only six of those were from experts. Practitioners called for organisations to be 'more proactive and delivering training and talk about the issues and help people understand better' (Participant P2). When asked about the consequences of technological uncertainty in a wealth management organisation, Participant $\mathrm{P} 4$ said:

Yeah, I think some organisations are looking to create their own platforms and train their staff in using those going forward. That is one way to handle the uncertainty.

(Participant P4)

As previously mentioned, lack of trust was cited as an antecedent to uncertainty by the experts. Interestingly, practitioners were more likely to perceive it as a consequence that followed the period of uncertainty. Of the 18 statements coded to this theme, 13 were from practitioners whereas only five were from experts. Participant $P 3$, used the analogy of a family going through crises and how the trust would breakdown if family members don't support each other to depict the loss of trust after a period of uncertainty:

You know like in a family when you are going through a crisis, you and your partner support each other, not become overly safe and say - hmm, there is something wrong with you, I should put you somewhere else. This is the same - in good times maybe the regulator and the market should be on the very opposite ends and in bad times they should probably come together to discuss what are the issues. Unfortunately, there is lot of blame game going on you did not tell us that there was market over-heating, you should have stopped us before we lent too much.

(Participant P3)

One of the critical differences in the perceptions of experts and practitioners was that loss of human resources due to uncertainty was discussed by all the practitioners but was never mentioned by any of the experts. When talking about the impact on human resources in the context of technological uncertainty in the wealth management sector, Participant P4 said:

One of the regulations required all investment advisers to have a professional qualification, where historically people have been grandfathered in. And people who had worked for 30-40 years with no financial qualification suddenly had to get a financial qualification. That there was obviously uncertainty within the industry to how many people would leave the industry because of that.

(Participant P4)

\section{7.3.2.3 Perception of uncertainty}

Although, both experts and practitioners perceived uncertainty as financial or learning opportunities, some professionals (four out of nine) attached negative 
connotations to the word 'uncertainty', and as such viewed it as something to be managed or avoided. Practitioners were more likely to report negative perceptions towards uncertainty compared to experts. Of the ten statements coded to this theme, seven were from practitioners and only three from experts. In response to what professionals typically do when they perceive uncertainty, Participant P2 said:

They do nothing, they become paralysed. So, you can find that people stop changing their jobs, get worried. That creates a world where internal rates of return projections are not acted on even though they are positive. That means that growth slows down. So that's the mess that we currently are in.

(Participant P2)

Even in statements made by experts, they talked about the negative impact of uncertainty in the context of practitioners, as evidenced in the quote below, by Participant E2 as they recounted the reactions of their employees after the 9/11 crises:

So, take for instance the 9/11 example. Even though it happened in the US, it was on the television screens. And everyone in the office was standing around and watching it on the screen, as the planes hit the towers. Now, we had contingencies in place, we had stop losses, and the European markets group but the people were just frozen looking at the screens. So, all the correct procedures were there but nothing happened. People literally could not respond. So again, the learning experience to me from that was that sometimes doing the calculations alone doesn't resolve the situation.

(Participant E2)

\section{7.4 Discussion and moving forwards}

Chapter 17 examined the antecedents and consequences of uncertainties perceived by finance professionals and their general perceptions towards these uncertainties. A lack of communication and a disconnect with the academic world were reported as the key antecedents to uncertainty. This is in conformance with the findings from Novin et al's., (1997) study that identified the need for more effective communication and interaction between educators and practitioners. 'Trust' was yet another substantial theme mentioned by seven out of nine professionals, in relation to the antecedent of uncertainty. Research within the change management literature has emphasised the role of communication and trust linked to the professionals' perceived uncertainty during turbulent times. Typically, loss of trust was seen as a consequence of perceived uncertainty, whereas lack of communication was found to be an antecedent of perceived uncertainty (Arnaout \& Esposito, 2018). The findings from Chapter 17 are in line with the previous studies with regards to the lack of communication being an antecedent of perceived uncertainty. However, it differs from the earlier findings, as a lack of trust was also noted as a potential antecedent to uncertainty along with being a consequence of uncertainty. 
Another substantial contribution of Chapter 17 to the existing literature is the comparison between the perceptions of experts versus practitioners. This comparison revealed that experts were more likely to indicate a lack of trust as an antecedent of uncertainty in contrast to practitioners who were more likely to report it as a consequence. Beyond the finance sector, a study carried out by Adobor (2006) in the pharmaceutical and biotechnology industry in the US and Canada, found that certain amount of uncertainty is necessary for the emergence of trust within the dealing parties, however beyond a particular threshold increase in uncertainty leads to a reduction in trust. Findings from this study conform to the findings of Adobor (2006) as practitioners reported the loss of trust as a likely consequence of uncertainty. This finding also adds to the literature on change management, as it highlights the importance of studying the role of trust and communication from multiple perspectives.

Furthermore, professionals recognised changes in training requirement that followed a period of uncertainty, whether it was objective environmental uncertainty or subjective perceived uncertainty. This means that when the cause of uncertainty was related to any external environmental factors such as regulatory changes or technological changes, changes in the training requirement was mandated by the government or organisations. However, when professionals perceived uncertainty, they responded by investing time and effort in reskilling or upskilling themselves. The findings were in line with Bohlinger et al.s (2015a) research examining workplace learning in uncertainty. They classified the challenges to learning under uncertainty under three levels:

- At the micro (individual) level, the onus is on the professionals to learn to manage continuous change as it is a key qualification for their employability.

- At the meso (organisational) level, the role of organisations is important in empowering their employees to manage uncertainty through upskilling, formal training, support for informal learning opportunities.

- At the macro-level (socio-political) upskilling of the global workforce.

An essential finding of this study was that finance professionals did not report high levels of negative perception towards uncertainty. For example, of the total statements coded in this study, only $1.14 \%$ of the codes were related to professionals talking about uncertainty negatively. This alludes to the possibility that finance professionals acknowledge and accept the fact that they work in a world of inherent uncertainty and they welcome it as a financial opportunity, or a learning opportunity or even something that they can manage.

Within the themes for perception of uncertainty, professionals specifically talked about uncertainty as a learning opportunity. Most of the empirical studies carried out around uncertainty look at how professionals make decisions or how they innovate in uncertainty (Freel, 2005) but there is very little focus on how they learn in uncertainty and findings from this study indicate that there is potential for further research. 


\subsection{Implications for practice}

There is value in perceiving uncertainty as a learning opportunity. From managing workforce well-being to ensuring business continuity, learning in the face of uncertainty is a priority for organisations in order to survive and thrive in uncertain times. Thus, organisations and professionals should be looking towards novel ways of learning and building a repertoire of best practices in the new normal characterised by uncertainty. An important implication for organisations is to exercise transparency and clearly communicate information related to uncertainty in order to prevent loss of trust of their employees in times of uncertainty. Findings from this chapter highlight the significance of understanding one's learning behaviour during uncertainty, as it has implications for organisations as well as professionals.

\section{References}

Adobor, H. (2006). Optimal trust? Uncertainty as a determinant and limit to trust in interfirm alliances. Leadership \& Organization Development Journal, 27(7), 537-553. doi:10.1108/ 01437730610692407

Arnaout, B., \& Esposito, M. (2018). The value of communication in turbulent environments: how SMEs manage change successfully in unstable surroundings. International Journal of Entrepreneurship and Small Business, 34(4), 500. doi:10.1504/ijesb.2018.10014545

Ashill, N. J., \& Jobber, D. (2010). Measuring state, effect, and response uncertainty: theoretical construct development and empirical validation. Journal of Management, 36(5), 1278-1308. doi:10.1177/0149206308329968

Billet, S. (2011). Subjectivity, self and personal agency in learning through and for work. In The SAGE handbook of workplace learning (pp. 60-72). London: SAGE Publications Ltd.

Bock, A. J., Opsahl,T., George, G., \& Gann, D. M. (2012). The effects of culture and structure on strategic flexibility during business model innovation. Journal of Management Studies, 49(2), 279-305. doi:10.1111/j.1467-6486.2011.01030.x

Bohlinger, S., Haake, U., Jorgensen, C. H., Toivianinen, H., \& Wallo, A. (2015a). Working and learning in times of uncertainty. doi:10.1007/978-94-6300-244-8

Bohlinger, S., Haake, U., Jorgensen, C. H., Toivianinen, H., \& Wallo, A. (Eds.). (2015b). Working and learning in times of uncertainty: challenges to adult, professional and vocational education. doi:10.1007/978-94-6300-244-8

Boshuizen, H., Bromme, R., \& Gruber, H. (2006). Professional learning: gaps and transitions on the way from novice to expert. Heidelberg: Springer Science \& Business Media.

Braun,V., \& Clarke,V. (2019). Reflecting on reflexive thematic analysis. Qualitative Research in Sport, Exercise and Health, 11(4), 589-597. doi:10.1080/2159676X.2019.1628806

Brown, W., Bryson, A., Forth, J., Whitfield, K., \& Kelly, J. (2011). The evolution of the modern workplace. Industrial Relations Journal, 42(3), 313-315. doi:10.1111/j.1468-2338. 2010.00603.x

Chaudhari,V. (2020). Learning in uncertainty: examining the relationship between perceived environmental uncertainty and self-regulated learning of finance professionals, and the role of technology in supporting it. Milton Keynes:The Open University.

Dow, S. (2010). The psychology of financial markets: Keynes, Minsky and emotional finance. The Elgar Companion to Hyman Minsky, 246-262. https://doi.org/10.32609/0042-87362010-1-99-113 
Downey, H. K., \& Slocum, J. (1975). Uncertainty: measures, research, and sources of vaiiatioa. Academy of Management Foumal, 3, 562-577.

Fenwick, T. (2001). Tides of change: new themes and questions in workplace learning. New Directions for Adult and Continuing Education, 200(92), 3-17. doi:10.1002/ace.36

Fløvik, L., Knardahl, S., \& Christensen, J. O. (2019). The effect of organizational changes on the psychosocial work environment: changes in psychological and social working conditions following organizational changes. Frontiers in Psychology, 10(December).doi:10.3389/ fpsyg.2019.02845

Fontana, R., Milligan, C., Littlejohn, A., \& Margaryan, A. (2015). Measuring self-regulated learning in the workplace. International Journal of Training and Development, 19(1), 32-52.

Freel, M. S. (2005). Perceived environmental uncertainty and innovation in small firms. Small Business Economics, 25(1), 49-64. doi:10.1007/s11187-005-4257-9

Gigerenzer, G. (2018). The heuristics revolution: rethinking the role of uncertainty in finance. The Behavioural Finance Revolution: A New Approach to Financial Policies and Regulations, 115-134. doi:10.4337/9781788973069.00020

Hertati, L. (2015). Impact of uncertainty of environment and organizational cultural on accounting information system management and implications for managerial performance. International Journal of Economics, Commerce, and Management, III(12), 455-468.

Iwaniec-Thompson, G. (2022). The identity trajectories of older academics: workplace affordances and individual subjectivities. In B. Rienties, R. Hampel, E. Scanlon, \& D. Whitelock (Eds.), Open world learning: research, innovation and the challenges of high-quality education (pp. 250-263). London: Routledge.

Jo, S., \& Sekkel, R. (2019). Macroeconomic uncertainty through the lens of professional forecasters. Journal of Business and Economic Statistics, 37(3), 436-446. doi:10.1080/073500 15.2017.1356729

March, J. G., \& Olsen, J. P. (1975). The uncertainty of the past: organizational learning under ambiguity. European Journal of Political Research, 3(2), 147-171. https://doi.org/10.1111/j. 1475-6765.1975.tb00521.x

Margaryan, A., Milligan, C., Littlejohn, A., Hendrix, D., \& Graeb-Koennerker, S. (2009). Self-regulated learning and knowledge sharing in the workplace. Organizational Learning, Knowledge and Capabilities Conference, 51(6), 51-2973. doi:10.5860/choice.51-2973

Markowska, M., \& Wiklund, J. (2020). Entrepreneurial learning under uncertainty: exploring the role of self-efficacy and perceived complexity. Entrepreneurship and Regional Development, 1-23. doi:10.1080/08985626.2020.1713222

Mayring, P. (2014). Qualitative content analysis. Theoretical foundation, basic procedures and software solution. In Sage.http://sgo.sagepub.com/content/4/1/2158244014522633. short

McKelvie, A., Haynie, J. M., \& Gustavsson, V. (2011). Unpacking the uncertainty construct: implications for entrepreneurial action. Journal of Business Venturing, 26(3), 273-292. doi:10.1016/j.jbusvent.2009.10.004

Michel, A., \& Wortham, S. (2009). Bullish on uncertainty: how organizational cultures transform participants. Cambridge: Cambridge University Press.

Milliken, F. J. (1987). Three types of perceived uncertainty about the environment: state, effect, and response uncertainty. Academy of Management Review, 12(1), 133-143. https:// doi.org/10.5465/AMR.1987.4306502

Muradoglu, G., \& Harvey, N. (2012). Introduction/guest editorial: behavioural finance:The role of psychological factors in financial decisions. Review of Behavioral Finance, 4(2), 68-80. doi:10.1108/19405971211284862 
Suri, H. (2011). Purposeful sampling in qualitative research synthesis. Qualitative Research Journal, 11(2), 63-75. https://search.proquest.com/docview/920894910/41BC7100662 04835PQ/1?accountid=13042

Vanevenhoven, J. (2012). Taxonomies of environmental uncertainty sources perceived by executives in the United states, Taiwan, and Mexico (Vol. 130, Issue 2). doi:10.1016/j.jaci.2012.05.050

Vecchiato, R., \& Roveda, C. (2011). Uncertainty, foresight, and strategic decision makingevidence from leading companies. In Forth international seville conference on future-oriented technology analysis (FTA) FTA and grand societal challenges - Shaping and driving structural and systemic transformations SEVILLE, 12-13 MAY 2011.

Wang, X., Qi, Y., \& Zhao, Y. (2019). Individual unlearning, organizational unlearning and strategic flexibility: The down-up change perspective. Baltic Journal of Management, 14(1), 2-18. doi:10.1108/BJM-10-2017-0324

Weiss, M., \& Wittmann, C. (2018). Objective environmental conditions and perceived environmental uncertainty: cognitive models as explanation for a perceptual gap. Journal of Accounting and Organizational Change, 14(1), 33-60. doi:10.1108/JAOC-11-2016-0079

Woolf, N. H., \& Silver, C. (2017). Qualitative analysis using NVivo: the five-level QDA® method. London: Routledge.

Zhao, Y., \& Wang, X. (2020). Organisational unlearning, relearning and strategic flexibility: from the perspective of updating routines and knowledge. Technology Analysis and Strategic Management, 1-13. doi:10.1080/09537325.2020.1758656 